\title{
Propuesta para rescatar la música y danza del Cantón La Maná - Provincia de Cotopaxi
}

\begin{abstract}
(c) (i) () ()
Proposal to rescue the music and dance of the Canton La Maná-Province of Cotopaxi
\end{abstract}

Cindy Estefania León Ganchozo. ${ }^{1}$, Natalia Geoconda Zambrano Cuadro. ${ }^{2}$, Gabriela Isabel Armas Cedeño. ${ }^{3}$ \& Olga Selena Rosero Pérez. ${ }^{4}$

Recibido: 10-11-2020 / Revisado: 28-11-2020 /Aceptado: 12-12-2020/ Publicado: 02-01-2021

\begin{abstract}
.
https://doi.org/10.33262/concienciadigital.v4i1.1522

Introduction: The proposal for the rescue of music and dance has important aspects since it enriches the knowledge of the population and mainly some genres considered representative also need to remember the different dances that were practiced at the time of their celebrations since dance is a valuable element in the process of training the human being, destined to get people confident, with possibilities to act in the world and responsible in their relationship with others. Objective. Rescue music and dance, so it is necessary to transmit the knowledge of the cultural identity that existed in the canton of La Maná. Methodology. In the following research the objective of achieving optimal results, the use of the following methods was chosen: quantitative method in which it is based on the obtaining of data or quantities and qualitative method that serves to obtain information or interpretative descriptions, therefore, work was worked with primary and secondary information. Results. $100 \%$ of the surveys applied to the 73 respondents represent that they do not know about any music or dance representative of the canton La Maná so it tells us that the rescue is important to be able to spread it and be known. Conclusion. Through the practice of music and dance part of our ancestors is rescued, in addition you can maintain interaction with the inhabitants and that young people can entertain themselves in something productive for them.
\end{abstract}

\footnotetext{
${ }^{1}$ Universidad Técnica de Cotopaxi Extensión La Maná, Ingeniería en Ecoturismo, La Maná - Ecuador., cindy.leon7623@utc.edu.ec, https://orcid.org/0000-0002-6356-5127

${ }^{2}$ Universidad Técnica de Cotopaxi Extensión La Maná, Ingeniería en Ecoturismo, La Maná - Ecuador., natalia.zambrano@utc.edu.ec, https://orcid.org/0000-0002-5678-7725

${ }^{3}$ Universidad Técnica de Cotopaxi Extensión La Maná, Ingeniería en Ecoturismo, La Maná - Ecuador., gabriela.armas0981@utc.edu.ec, https://orcid.org/0000-0001-8484-9447

${ }^{4}$ Universidad Técnica de Cotopaxi Extensión La Maná, Ingeniería en Ecoturismo, La Maná - Ecuador., olga.rosero3507@utc.edu.ec, https://orcid.org/0000-0003-2121-6436
} 
Keywords: Rescue, music, dance, identity, diffusion.

\section{Resumen.}

Introducción: La propuesta para el rescate de la música y danza tiene aspectos importantes ya que enriquece el conocimiento de la población y principalmente surgieron algunos géneros considerados representativos además es necesario recordar las diferentes danzas que se practicaban al momento de sus celebraciones ya que la danza es un elemento valioso en el proceso de formación del ser humano, destinado a conseguir personas seguras de sí mismas, con posibilidades de actuar en el mundo y responsables en su relación con los demás. Objetivo. Rescatar la música y la danza, por lo que es necesario transmitir los conocimientos de la identidad cultural que existió en el cantón La Maná. Metodología. En la siguiente investigación el objetivo de conseguir resultados óptimos, se optó por la utilización de los siguientes métodos que son: método cuantitativo en la cual se basa en la obtención de datos o cantidades y método cualitativo que sirve para la obtención de información o descripciones interpretativas, por ende, se trabajó con información primaria y secundaria. Resultados. El 100\% de las encuestas aplicadas a los 73 encuestados representa a que no conocen sobre alguna música o danza representativa del cantón La Maná por lo que nos indica que es importante el rescate para poder difundirla y sea conocida. Conclusión. A través de la práctica de la música y danza se rescata parte de nuestros antepasados, además se puede mantener la interacción con los habitantes y que los jóvenes puedan entretenerse en algo productivo para ellos.

Palabras claves: Rescate, música, danza, identidad, difusión.

\section{Introducción.}

El Ecuador a lo largo de su historia se ha caracterizado por sus diversas culturas, nuestra música y nuestra danza. La música ecuatoriana es uno de los patrimonios culturales intangibles del Ecuador, y en las últimas décadas se ha ido reemplazando y olvidando el valor cultural de los mismos. La música posee un aporte potencial para fortalecer la identidad cultural.

Según Sandoval, (2009) La etnomusicología, inicialmente, ha tenido que ver con la música viva de las tradiciones orales, incluidos los instrumentos musicales y danzas de los pueblos ágrafos, dentro del denominado "folclore rural".

Compartimos con Montúfar, (2011) cuando confirma que se indica que surgieron algunos géneros considerados representativos de Ecuador, tales como: El Pasillo, el Yaraví, el Fandango o El Pasacalle. Estos utilizan instrumentos particulares de las regiones ecuatorianas y por eso, se volvieron bastante populares en fiestas tradicionales y hasta en la cotidianidad de los ecuatorianos. 
(Montúfar, 2011) Nos comparte también que la danza es un elemento valioso en un proceso de formación del ser humano, destinado a conseguir personas seguras de sí mismas, con posibilidades de actuar en el mundo y responsables en su relación con los demás. El culto a las tradiciones que venían de generación en generación se interrumpe con la llegada de los españoles a América.

En la provincia de Cotopaxi es necesario recordar las diferentes danzas que se practicaban al momento de sus celebraciones, con lo cual nacen las fiestas populares que enmarcaron en los años anteriores, los bailes indígenas y campesinas acostumbran hacerlo como regocijos públicos o religiosos, en otros lugares lo hacen por amor al arte y mostrar la identidad cultural de la localidad.

Según Álvarez, (2015) hasta la actualidad en las comunidades indígena tocan con instrumentos autóctonos, interpretan albazos, aires típicos, sanjuanitos, tonadas, danzante, caporales, yaravíes, melodías que le dan ritmo y alegría a la existencia misma del ser humano.

En el cantón La Maná la música y danza se ha ido perdiendo debido a que los grupos danzantes en la actualidad optan por músicas modernas, mientras que la música original-tradicional con la cual ellos se identificaban culturalmente, le han dado poca importancia los niños, jóvenes y adultos, en medio de este entorno natural a medida que ha pasado el tiempo, sus pobladores han venido desarrollando fiestas religiosas de acuerdo a su vocación en homenaje a San Vicente Ferrer, la Virgen del Cisne, San Marcos y San Pablo, años anteriores se lo festejaba con juegos pirotécnicos, desfiles, bailes tradicionales y en la actualidad se realiza el arreglo de la iglesia en la que se realiza misas, procesiones y bailes populares.

La presente investigación tiene el objetivo de rescatar la música y la danza, por lo que es necesario transmitir los conocimientos de la identidad cultural que existió en el cantón La Maná. Para ello hemos encontrado necesario, investigar qué tipo de música y danza que mantuvieron ancestralmente mediante una investigación FODA, realizando inventarios y fichas técnicas de las parroquias urbanas y rurales para tener una información primaria. En la actualidad se pretende difundir la información para el fortalecimiento intelectual de los niños, jóvenes y adultos que no tiene conocimiento de la cultura que poseen los lugares donde ellos habitan.

\section{Metodología.}

En la siguiente investigación el objetivo de conseguir resultados óptimos, se optó por la utilización de los siguientes métodos que son: método cuantitativo en la cual se basa en la obtención de datos o cantidades y método cualitativo que sirve para la obtención de información o descripciones interpretativas, por ende se trabajó con información primaria que consiste en (visitas in situ, levantamiento de información, entrevistas, encuestas, observación, documentos, matriz FODA, fichas técnicas respecto al instructivo para fichas de registro de inventario del patrimonio cultural inmaterial INPC, (2011) y la georreferenciación del lugar), con representantes del GAD Municipal La Maná, EMTURCOM-LM, GAD`s Parroquiales de Guasaganda y Pucayacu, academia, turistas 
locales y nacionales. También se trabajó por medio de las fuentes de información secundaria (revistas científicas, tesis, artículos, sitios web como: Instituto Nacional de Patrimonio Cultural y Ministerio de Turismo).

Se utilizó la fórmula de la muestra para determinar la población de La Maná, según él (INEC, 2010) la población del cantón es de 42.216 habitantes, con la técnica de muestreo se definió el total de las encuestas aplicadas.

Para poder calcular la muestra objetiva se utilizó la siguiente formula según (Pickers, 2015) la fórmula para calcular el tamaño de muestra cuando se desconoce el tamaño de la población es la siguiente:

$$
n=\frac{Z a^{2} * p * q}{d^{2}}
$$

\section{En donde:}

- $\quad \mathbf{N}=$ Número poblacional.

- $\quad \mathbf{Z}=$ Nivel de confianza $=1,96$ al cuadrado (si la seguridad es del 95\%).

- $\quad \mathbf{P}=$ Probabilidad de éxito, o proporción esperada (en este caso $5 \%=0.5$ ).

- $\quad \mathbf{Q}=$ Probabilidad al fracaso $=1-\mathrm{p}$ (en este caso 1-0.05=0.95).

- $\quad \mathbf{D}=$ Precisión “Error máximo admisible en términos de proporción” (5\%=0.05). (Pickers, 2015)

$$
\begin{gathered}
n=\frac{N * Z^{2} a * p * q}{d^{2} *(N-1)+Z^{2} a * p * q} \\
n=\frac{42216 * 1.96^{2} * 0.05 * 0.95}{0.05^{2} *(42216-1)+1.96^{2} * 0.05 * 0.95} \\
n=73 \text { encuestas }
\end{gathered}
$$

Con la utilización de la fórmula de muestreo se calcula la muestra representativa, donde se obtuvo un total de 73 encuestas, en la cual se aplicó un instrumento de investigación estructurado (Cuestionario), aplicándola en La Maná y en la Parroquia de Guasaganda, con la finalidad de conocer si la propuesta del rescate de la danza y música tradicional del Cantón La Maná ayuda para la aportación y fortalecimiento de la identidad cultural de la misma antes mencionada, reflejándonos resultados muy positivos. También se utilizó la técnica de observación y por medio del método descriptivo se realizó una descripción concreta de todas las danzas y músicas del lugar, realizando una interpretación de la matriz FODA (Fortalezas, Oportunidades, Debilidades y Amenazas), y también plasmando toda la información recopilada a través del instructivo para fichas del inventario inmaterial según el INPC (2011, p. 160-161), ámbito A2: Artes del Espectáculo y, Subámbito 2.1 Danza y 2.3. Música. 
Tabla $N^{\circ} 1$ : Música y Danza del Cantón La Maná.

Denominación Categoría Ámbito Subámbito Datos de localización $\quad$ Descripción

Fotografía

Nota: Inventario de la música y la danza del cantón La Maná

Fuente: (Cindy León, 2020)

\section{Resultados}

\section{Música y Danza.}

\section{Música y Danza}

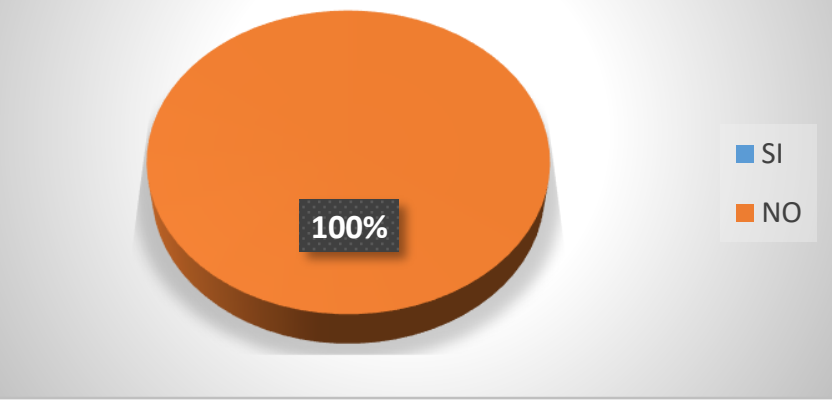

Figura 1: Auto identificación en porcentajes del desconocimiento de la música y danza del cantón La Maná.

Fuente: Cindy León et al. 2020.

Análisis: El 100\% de las encuestas aplicadas a los 73 encuestados representa a que no conocen sobre alguna música o danza representativa del cantón La Maná por lo que nos indica que es importante el rescate para poder difundirla y sea conocida.

\section{Género Musical.}

\section{Género Musical}

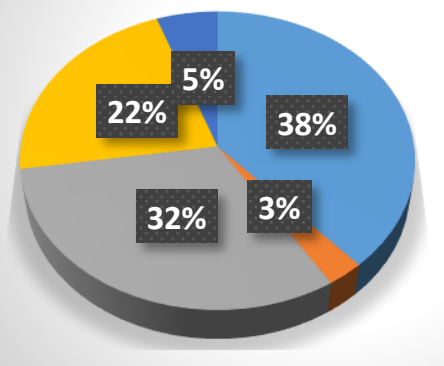

$$
\begin{aligned}
& \text { Pasacalle } \\
& \text { - Yaraví } \\
& \text { San Juanito } \\
& \text { Pasillo } \\
& \text { Albazo }
\end{aligned}
$$

Figura 2: Auto identificación en porcentajes del género musical. Fuente: Cindy León et al. 2020. 
Análisis 2: El género de música tradicional que obtuvo mayor porcentaje fue el Pasacalle con un $38 \%$, el género San Juanito obtuvo un 32\%, el género Pasillo esta entre el 22\%, el género albazo con un 5\% y el último género que es el Yaraví está en un 3\%.

\section{Discusión}

Según en él (PDOT, 2015-2020), La Maná está localizado en las estribaciones de la cordillera occidental de los Andes, en la provincia de Cotopaxi, a $150 \mathrm{~km}$ de Latacunga capital de la provincia. Morfológicamente se ubica sobre una llanura de pie de cordillera compuesta de depósitos Aluviales cubiertas de cenizas y arenas volcánicas de origen desconocido. La cabecera cantonal se asienta sobre una terraza aluvial antigua del río San Pablo. Tiene varios pisos climáticos que varía de subtropical a tropical (Altura variable de 200 y $1150 \mathrm{msnm}$ ).

Nos manifiesta la UNESCO, (2019) que el El patrimonio cultural inmaterial o "patrimonio vivo" se refiere a las prácticas, expresiones, saberes o técnicas transmitidos por las comunidades de generación en generación. El patrimonio inmaterial proporciona a las comunidades un sentimiento de identidad y de continuidad: favorece la creatividad y el bienestar social, contribuye a la gestión del entorno natural y social y genera ingresos económicos. Numerosos saberes tradicionales o autóctonos están integrados, o se pueden integrar, en las políticas sanitarias, la educación o la gestión de los recursos naturales.

UNESCO, (2019) Nos comparte que el patrimonio cultural inmaterial engloba prácticas culturales vivas tales como las tradiciones culturales, las artes del espectáculo, las prácticas sociales, los ritos y acontecimientos festivos, los conocimientos y prácticas relativos a la naturaleza y el universo o los conocimientos relacionados con la artesanía tradicional. (UNESCO, 2019)

La Convención de la UNESCO, (2003) para la Salvaguardia del Patrimonio Cultural Inmaterial tiene como objetivo la conservación de este frágil patrimonio; también pretende asegurar su viabilidad y optimizar su potencial para el desarrollo sostenible. La UNESCO brinda su apoyo en este ámbito a los Estados Miembros mediante la promoción de la cooperación internacional para la salvaguardia, y estableciendo marcos institucionales y profesionales favorables a la preservación sostenible de este patrimonio vivo. (UNESCO, 2019)

El espectáculo es un fenómeno social y cultural, en ella se puede apreciar una gran variedad de expresiones e interpretaciones las que dependerán de la diversidad y heterogeneidad social, étnica y lingüística de los pueblos y sociedades que la celebran. El aporte que se quiere es encaminar a los niños, jóvenes y adultos a que conozcan más de la música y danza tradicional que posee el cantón ya que es importante tener conocimiento del mismo para que las personas visitantes tengan conocimiento de la cultura que tiene La Maná. Al promover la música y danza tradicional del cantón La Maná se irá mejorando en el rescate, ya que por la aculturación que se da en todos los lugares del país es la razón principal que las comunidades han dado por pérdida las culturas tradicionales y costumbres que nuestros antepasados han dejado como representación propia. 
ISSN: 2600-5859

WWW.concienciadigital.org

Vol. 4, N¹, p. 22-33, Enero-Marzo, 2021

Tabla No2: Música y Danza del Cantón La Maná.

\begin{tabular}{|c|c|c|c|l|l|}
\hline $\begin{array}{c}\text { Denomina } \\
\text { ción }\end{array}$ & Categoría & Ámbito & Subámbito & \multicolumn{1}{c|}{$\begin{array}{c}\text { Datos de } \\
\text { localización }\end{array}$} & \multicolumn{1}{c|}{ Descripción } \\
\hline $\begin{array}{c}\text { Música } \\
\text { Tierra } \\
\text { Fecunda }\end{array}$ & $\begin{array}{c}\text { Manifestació } \\
\text { n Cultural }\end{array}$ & $\begin{array}{c}\text { Artes del } \\
\text { Espectáculo }\end{array}$ & Música & $\begin{array}{l}\text { Parroquia: La Maná } \\
\text { Coordenadas: } \\
\text { X } 697643 \\
\text { Y } 9895912\end{array}$ & $\begin{array}{l}\text { Esta canción es una composición } \\
\text { original en letra y música que se ha } \\
\text { hecho en honor al Cantón La } \\
\text { Maná. }\end{array}$ \\
\hline
\end{tabular}

Figura 1. Reconocimiento a la Sra. Teresa Acurio

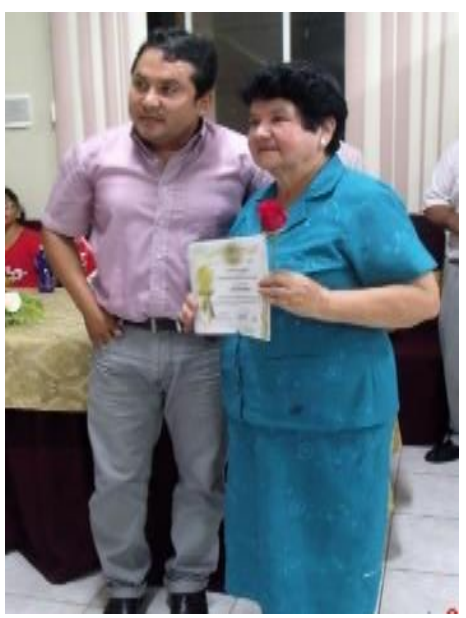

Fuente: (Conozcamos La Maná, 2020)

\begin{tabular}{|c|c|l|l|l|l|}
\hline $\begin{array}{c}\text { Música } \\
\begin{array}{c}\text { Pucayacu } \\
\text { querido }\end{array}\end{array}$ & $\begin{array}{c}\text { Manifestació } \\
\text { n Cultural }\end{array}$ & $\begin{array}{c}\text { Artes del } \\
\text { Espectáculo }\end{array}$ & Música & $\begin{array}{l}\text { Parroquia: Pucayacu. } \\
\text { Coordenadas: } \\
\text { X 697331 } \\
\text { Y } 895711\end{array}$ & $\begin{array}{l}\text { Esta canción es la única } \\
\text { composición inédita en letra y } \\
\text { música que se ha hecho en honor a } \\
\text { larroquia Además, cabe } \\
\text { mencionar que Celso Vega } \\
\text { también acompaña a este dúo } \\
\text { tocando el acordeón. }\end{array}$ \\
\hline
\end{tabular}

Figura 2. Don Araque y el Lic. Pichucho entonando.

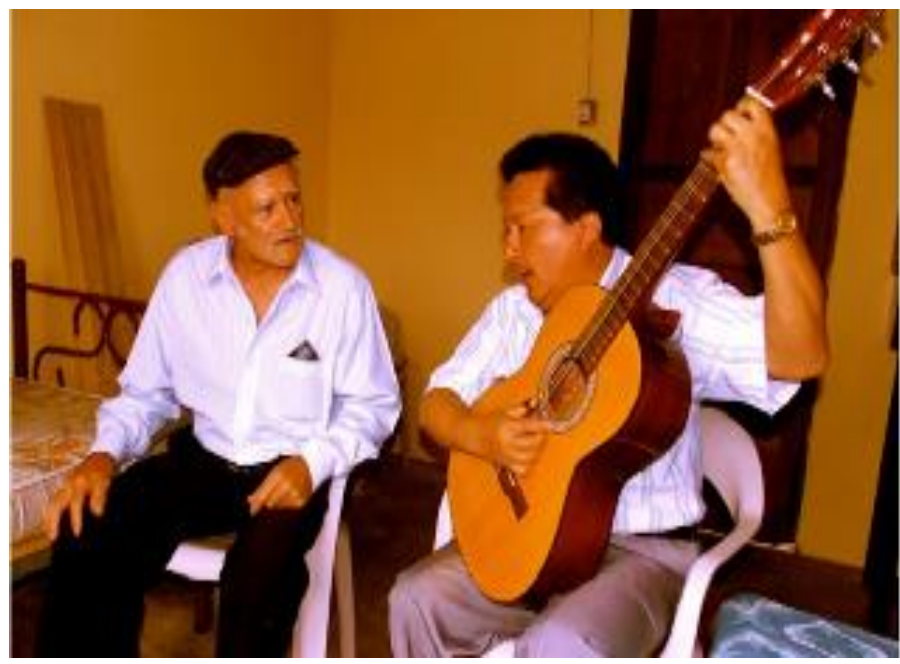

Fuente: (Rosero, 2020) 
Tabla No3: Música y Danza del Cantón La Maná.

\begin{tabular}{|c|c|c|c|c|c|}
\hline $\begin{array}{c}\text { Denomina } \\
\text { ción }\end{array}$ & Categoría & Ámbito & Subámbito & $\begin{array}{c}\text { Datos de } \\
\text { localización }\end{array}$ & \multicolumn{1}{c|}{ Descripción } \\
\hline $\begin{array}{c}\text { Danza los } \\
\text { Faccha } \\
\text { Huayras }\end{array}$ & $\begin{array}{c}\text { Manifestaci } \\
\text { ón Cultural }\end{array}$ & $\begin{array}{c}\text { Artes del } \\
\text { Espectáculo }\end{array}$ & Danza & $\begin{array}{l}\text { Parroquia: La Maná } \\
\text { Coordenadas: } \\
\mathbf{X} 697643 \\
\mathbf{Y 9 8 9 5 9 1 2}\end{array}$ & $\begin{array}{l}\text { Los temas musicales que interpretan } \\
\text { los graban en kichwa y español, y la } \\
\text { letra de sus composiciones habla de la } \\
\text { vida de juventud, de las problemáticas } \\
\text { que hay en las comunidades y de } \\
\text { rupturas amorosas. }\end{array}$ \\
\hline
\end{tabular}

Figura 3. Grupo de danza Los Faccha Huayras

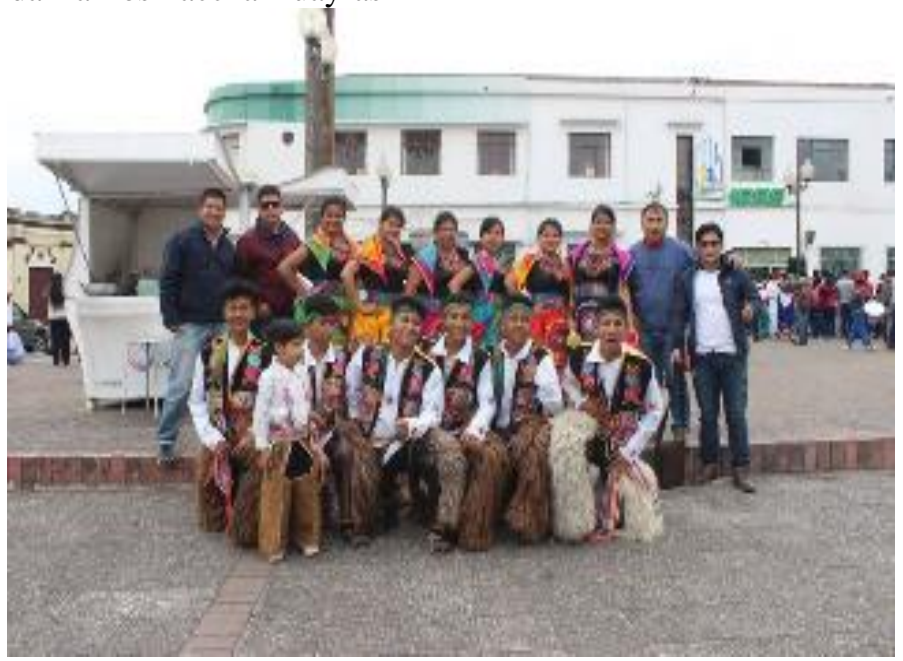

Fuente: (Pilar, 2020)

\begin{tabular}{|c|c|c|c|l|l|}
\hline $\begin{array}{c}\text { Himno } \\
\text { Unidad } \\
\text { Guasagand } \\
\text { a }\end{array}$ & $\begin{array}{c}\text { Manifestaci } \\
\text { ón Cultural }\end{array}$ & $\begin{array}{c}\text { Artes del } \\
\text { Espectáculo }\end{array}$ & Música & $\begin{array}{l}\text { Parroquia: La Maná } \\
\text { Coordenadas: } \\
\text { X 705099 }\end{array}$ & $\begin{array}{l}\text { La importancia que tiene una unidad } \\
\text { educativa de esta capacidad que tiene } \\
\text { 29 docentes y desde aquí proyecta lo } \\
\text { mejor de cada uno para catalogar en la } \\
\text { mente y el corazón de los estudiantes. }\end{array}$ \\
\hline
\end{tabular}

Figura 4. Unidad Educativa Guasaganda.

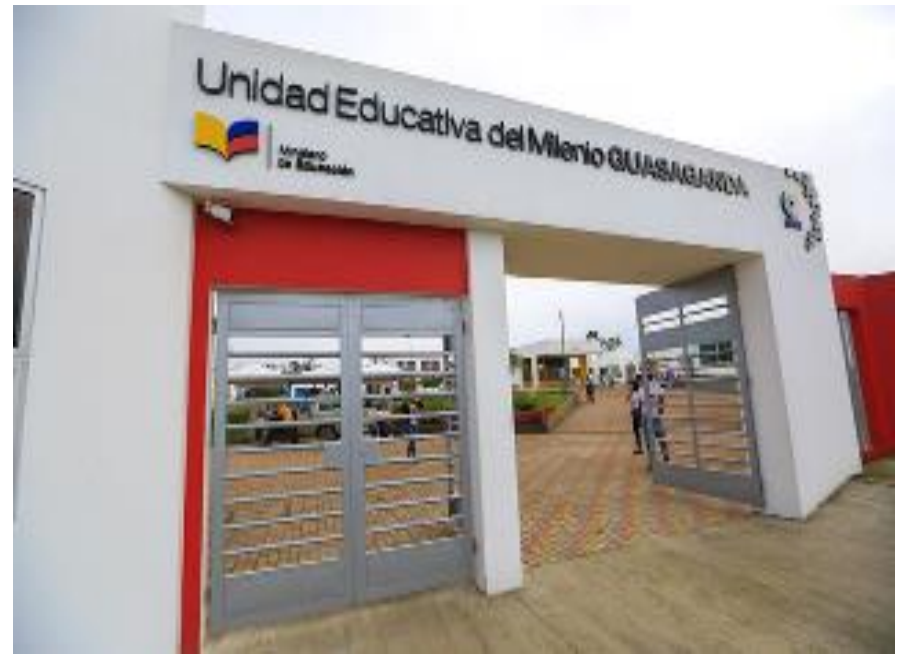

Fuente: (Armas, 2020) 
ISSN: 2600-5859

WWW.concienciadigital.org

Vol. 4, N¹, p. 22-33, Enero-Marzo, 2021

Tabla Nº: Música y Danza del Cantón La Maná.

\begin{tabular}{|c|c|c|c|l|l|}
\hline $\begin{array}{c}\text { Denomi } \\
\text { nación }\end{array}$ & Categoría & Ámbito & Subámbito & \multicolumn{1}{c|}{$\begin{array}{c}\text { Datos de } \\
\text { localización }\end{array}$} & \multicolumn{1}{c|}{ Descripción } \\
\hline $\begin{array}{l}\text { Danzante } \\
\text { Pucayacu }\end{array}$ & $\begin{array}{c}\text { Manifestación } \\
\text { Cultural }\end{array}$ & $\begin{array}{c}\text { Artes del } \\
\text { Espectáculo }\end{array}$ & Danza & $\begin{array}{l}\text { Parroquia: Pucayacu. } \\
\text { Coordenadas: } \\
\text { X 697331 } \\
\text { Y 895711 }\end{array}$ & $\begin{array}{l}\text { El folklore o folclore hace referencia } \\
\text { a las costumbres y tradiciones de una } \\
\text { comunidad. }\end{array}$ \\
\hline
\end{tabular}

Figura 5. Grupo danzante Pucayacu

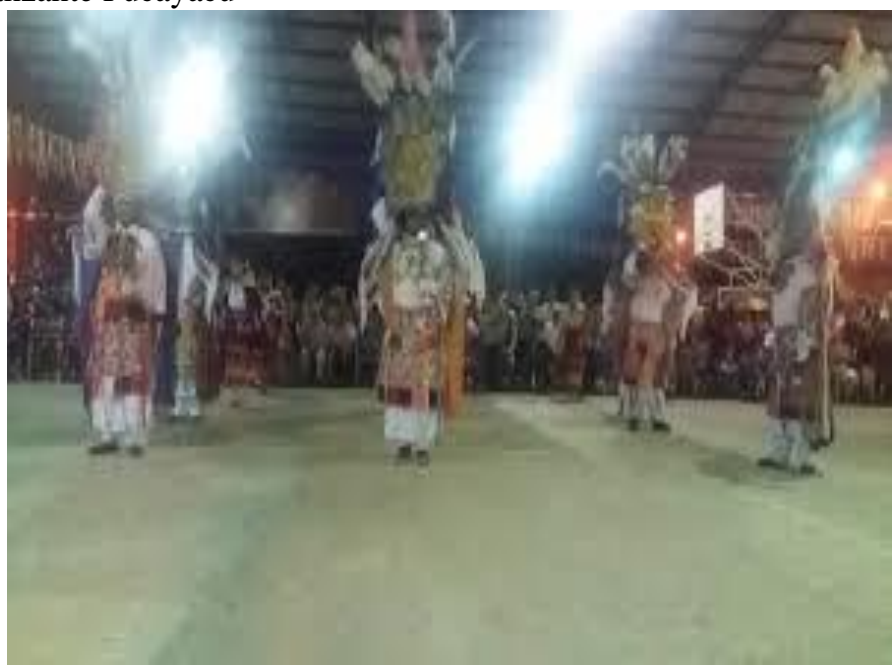

Fuente: (Noboa, 2020)

\begin{tabular}{|c|c|c|c|c|c|}
\hline $\begin{array}{c}\text { Danza } \\
\text { Vientos } \\
\text { Andinos }\end{array}$ & $\begin{array}{l}\text { Manifestación } \\
\text { Cultural }\end{array}$ & $\begin{array}{l}\text { Artes del } \\
\text { Espectáculo }\end{array}$ & ıza & $\begin{array}{l}\text { Parroquia: } \\
\text { Guasaganda. } \\
\text { Coordenadas: } \\
\text { X } 705099 \\
\text { Y } 9911153\end{array}$ & $\begin{array}{l}\text { Dentro de la música andina se } \\
\text { destaca el San Juanito el mismo que } \\
\text { representa un género musical dentro } \\
\text { de la música andina sus orígenes son } \\
\text { de la provincia de Imbabura. }\end{array}$ \\
\hline
\end{tabular}

Figura 6. Grupo de danza Los vientos andinos.

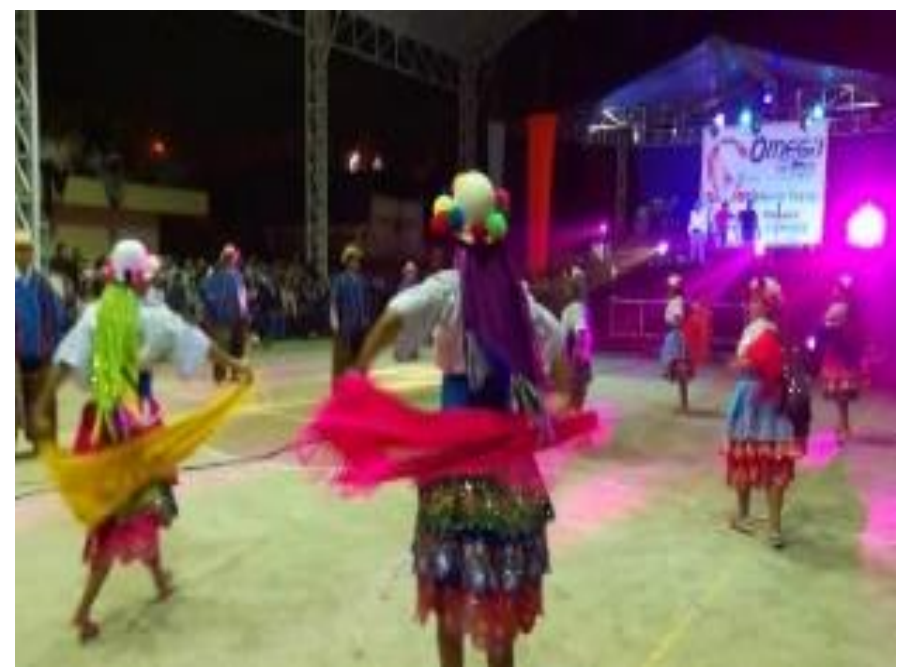

Fuente: (Burbano, 2020)

Nota: Inventario de la música y la danza del cantón La Maná.

Fuente: (Cindy León, 2020) 


\section{Conclusiones.}

- A través de la práctica de la música y danza se rescata parte de nuestros antepasados, además se puede mantener la interacción con los habitantes y que los jóvenes puedan entretenerse en algo productivo para ellos.

- Se determina que las personas a través de las encuestas desarrolladas el $100 \%$ de la población desconocen, la música y danza que tienen el cantón la Maná, y por medio de la misma aprueban que se dé el rescate de estas culturas tradicionales ya que es muy importante conocerlas y que las futuras generaciones las practiquen.

- La música y danza proporciona un gran beneficio ya que permite estar al cabo de la música tradicional y así ayuda a que los grupos danzantes opten por la música propia que tiene el cantón ya que siempre han preferido músicas folclóricas de la sierra ecuatoriana sin tomar en cuenta la importancia que tiene la propia música que posee el lugar a quien ellos representan.

\section{Referencias Bibliográficas.}

Álvarez, M. (Abril de 2015). "Rescate de las danzas autóctonas de Cotopaxi, del cantón Salcedo, para afianzar la interculturalidad en los niños del primer año de educación básica de la escuela cristóbal colón en el cantón salcedo. Recuperado el 17 de Noviembre de 2020, de http://repositorio.utc.edu.ec/bitstream/27000/2995/1/T-UTC-00461.pdf

Armas, G. (12 de Octubre de 2020). Unidad Educativa Guasaganda. La Maná, Cotopaxi, Ecuador.

Burbano, P. (12 de Octubre de 2020). Grupo de danza Los vientos andinos. La Maná, Cotopaxi, Ecuador.

Conozcamos La Maná. (07 de Octubre de 2020). Conozcamos La Maná. Recuperado el 10 de Octubre de 2020 , de https://www.facebook.com/542776652495408/posts/3073500872756294/

INEC. (12 de MARZO de 2010). Instituto Nacional de Estadística y Censos. Recuperado el 17 de Noviembre de 2020, de https:/www.ecuadorencifras.gob.ec/wp-content/descargas/Manulateral/Resultados-provinciales/cotopaxi.pdf

INPC. (06 de Mayo de 2011). Instituto Nacional de Patromonio Cultural . Recuperado el 17 de Noviembre de 2020, de https://downloads.arqueoecuatoriana.ec/ayhpwxgv/noticias/publicaciones/INPC-X-

InstructivoParaFichasDeRegistroInventarioPatrimonioInmaterial.pdf

Montúfar, K. (8 de Noviembre de 2011). Danza del Ecuador. Recuperado el 17 de Noviembre de 2020, de file:///C:/Users/user/Downloads/Tesis\%20-\%20Karla\%20Mont\%C3\%BAfar.pdf 
Noboa, N. (15 de Octubre de 2020). Grupo danzante Pucayacu. La Maná, Cotopaxi, Ecuador.

PDOT. (2015-2020). Plan de Desarrollo y Ordenamiento Terriotorial del Cantón La Maná. Recuperado el 17 de Noviembre de 2020, de http://app.sni.gob.ec/snilink/sni/PORTAL_SNI/data_sigad_plus/sigadplusdocumentofinal/0560000890001_Pdyot \%20La\%20Man\%C3\%A1\%202015_22-03-2016_16-42-48.pdf

Pickers, S. (04 de Noviembre de 2015). Passionate People, Creative Solutions. Recuperado el 17 de Noviembre de 2020, de https://www.psyma.com/company/news/message/comodeterminar-el-tamano-de-una-muestra

Pilar, Y. (22 de Octubre de 2020). Grupo de danza Los Faccha Huayras . La Maná, Cotopaxi, Ecuador.

Rosero, O. (12 de Octubre de 2020). Don Araque y el Lic. Pichucho entonando. La Maná, Cotopaxi, Ecuador.

Sandoval , J. (Julio de 2009). Música patrimonial del Ecuador. Recuperado el 17 de Noviembre de 2020, de https://biblio.flacsoandes.edu.ec/libros/digital/52868.pdf

UNESCO. (2003). Organización de las Naciones Unidas para la Educación, la Ciencia y la Cultura . Recuperado el 17 de Noviembre de 2020, de https://ich.unesco.org/es/convenci\%C3\%B3n

UNESCO. (2019). Organización de las Naciones Unidas para la Educación, la Ciencia y la Cultura . Recuperado el 17 de Noviembre de 2020, de https://es.unesco.org/news/musicadanza-artesania-poesia-y-juegos-tradicionales-orden-del-dia-novena-reunion-del-comite0

UNESCO. (2019). Organización de las Naciones Unidas para la Educación, la Ciencia y la Cultura . Recuperado el 17 de Noviembre de 2020, de https://es.unesco.org/themes/patrimonio-cultural-inmaterial

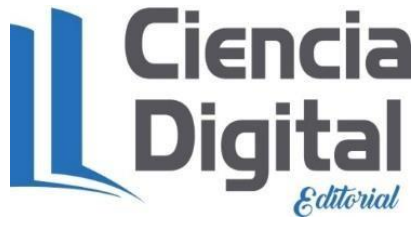




\section{PARA CITAR EL ARTÍCULO INDEXADO.}

León Ganchozo, C. E., Zambrano Cuadro, N. G., Armas Cedeño, G. I., \& Rosero Pérez, O. S. (2021). Propuesta para rescatar la música y danza del Cantón La Maná - Provincia de Cotopaxi. ConcienciaDigital, 4(1), 22-33. https://doi.org/10.33262/concienciadigital.v4i1.1522

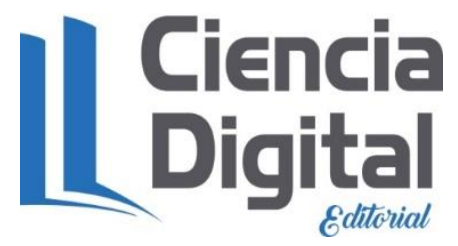

El artículo que se publica es de exclusiva responsabilidad de los autores y no necesariamente reflejan el pensamiento de la Revista Conciencia Digital.

El artículo queda en propiedad de la revista y, por tanto, su publicación parcial y/o total en otro medio tiene que ser autorizado por el director de la Revista Conciencia Digital.

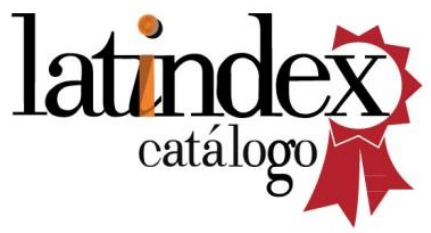

